\title{
In-Vitro Antibacterial, Antifungal and Qualitative Phytochemical Analysis of Three Medicinal Plants of Lahore, Punjab
}

\section{Nureen Zahra ${ }^{1 *}$, Abdullahi Aliyu ${ }^{1}$, Aysha Shaukat ${ }^{2}$, Muhammad Junaid Arif ${ }^{1}$, Muhammad Usman $^{1}$, Ahmed Saleem ${ }^{1}$ and Modasrah Mazhar ${ }^{3}$}

${ }^{1}$ Institute of Molecular Biology and Biotechnology, University of Lahore, Pakistan

${ }^{2}$ University Institute of Radiology Sciences and Medical Imaging Technology, Pakistan

${ }^{3}$ Department of Eastern Medicine and Surgery, Qarshi University Lahore, Pakistan

*Corresponding Author: Nureen Zahra, Institute of Molecular Biology and Biotechnology, University of Lahore, Pakistan.

Received: October 03, 2019; Published: November 07, 2019

DOI: $10.31080 /$ ASMI.2019.02.0429

\begin{abstract}
Background: To overcome the escalating problems associated with the infectious disease and drug resistance presented by pathogenic microorganisms have directed the needs for the screening of several medicinal plants for their potential antimicrobial activity. The present study aimed to carry out an in-vitro antibacterial, anti-fungal activity and qualitative phytochemical analysis of three medicinal plants of Punjab, Lahore.

Method: Fresh sample of Carica papaya, Eugenia jambolana and Seriphidium kurramense were collected in the local area of Punjab and the selected isolated were tested against aqueous and ethanolic extracts of the three plants. Antimicrobial activity was determined by disc diffusion method.

Results: Qualitative phytochemical screening showed the presence of phytochemicals in both aqueous and ethanolic. It was found that most plants extracts studied had antibacterial activity. Eugenia jambolana and Seriphidium kurramense ethanolic extracts shows high activity on almost all the isolated bacteria. Carica papaya and Seriphidium kurramense shows antifungal activity on ethanolic and water stem respectively.

Conclusions: It was concluded that from the results obtained that the plants parts fractions were significant in possessing antibacterial, antifungal activities. Among all the ethanol was found to be most important fraction at its high concentration.

Keywords: Phytochemical, Antibacterial, Seriphidium kurramense
\end{abstract}

\section{Introduction}

Medicinal plants contain biochemical compound that has antimicrobial properties. These compound are applicable as they have being long in used as traditional medicine. Effective plant extracts used to treat human disease has additional advantage in low production and accessibility to rural community [1].

In a day more than 50000 people died worldwide as a result of infectious disease.in developing countries morbidity and mortality are the major problem. E. coli, Salmonella typhi, S. aureus are most common etiological agents [2].These diseases are debilitating factor and ultimately cause death in millions of people worldwide. Indiscriminate use of drugs leads to multidrug resistance [3].

Antibiotics are organic substances that at low concentration inhibits the growth or destroy bacteria [4]. The side effects of some antibiotics leads to their limitation in use. Therefore new drugs with less side effect is require to be discovered [5]. For the relief from sickness medicinal plants may be used. Being it a beyond a shadow of doubt on an art as old as mankind. Plant extracts are expected to be active against drugs resistance microbes [6].

Medicinal plants contain biochemical compound that has antimicrobial properties. These compound are applicable as they have being long in used as traditional medicine. Effective plant extracts used to treat human disease has additional advantage in low production and accessibility to rural community [1].

For the therapeutic treatments the plants parts with a known antimicrobial properties can be of great significant. Due to secondary metabolites synthesized by plants leads to the usage of plants because of their antimicrobial effects [6]. The plants extracts or their active compound have been used for the traditional medicine in about $80 \%$ of world populations [2].

Due to wide spreading of infectious diseases, side effects of antibiotics and bacterial resistance to antibiotics, identification medicinal plant and purification of their active compounds are useful 
in the treatment of diseases. Medicinal plants not only involved in the treatment of infectious diseases but at the same time reduce a large number of antibiotic side effects [3].

The family Caricaceae contain Carica papaya which has the common names as pawpaw tree, papaya etc. The plants parts mostly used in traditional medicine include the leaves, fruit, and seeds. Morphological measured approximate $7-10 \mathrm{~m}$ tall and about $20-25 \mathrm{~cm}$ in diameter. The plant also inhabit in almost everywhere in Asian countries and Africa especially Nigeria. Chymopapain and papain are the active biochemical compounds found in Carica papaya that aids in digestion [7].

Eugenia jambolana, is a member of the family myrtaceae morphologically the shape is glabrous, colour of the bark is pale brown and the plant is up to 35 meter in height and 3 meter in diameter. The leaves are $7-15 \mathrm{~cm}$ long and the tip of leaves are shortly pointed [8]. The fruits have different size up to $3 \mathrm{~cm}$ long, the shape is ellipsoid or oblong. Eugenia jambolana mostly known as jambul or black plum. The Eugenia jambolana tree is mostly found in Asian countries like India, Bangladesh, Nepal, Pakistan, Srilanka, Indonesia, and Eastern Africa. Many report showed that Eugenia jambolana contain phytochemicals like glycosides, phenols, tannins, flavonoids and steroids, coumarin. The various part of Eugenia jambolana had got therapeutic applications like it barks for the treatment of bowels, anthelmintic. The seeds are strongly effective as anti-inflammatory, antibacterial and antidiarrheal [9].

The genus Seriphidium belonging to the family Asteraceae (Composite) commonly known as mug wort, wormwood and sagebrush. They are of great importance commercially as it contain some essential biochemical component that can be used for the treatment of disease [10]. The genus consists of small herbs and shrubs and commonly found in northern temperate regions and comprises more than 500 species from South Asia, North America and European countries. Terpenoides and sesquiterpene lactones are present in the plant that makes most of the species have strong aromas and bitter tastes, which serve as repellant that makes it have a selective advantage [11]. The plant of the genus Seriphidium is also a good antimalarial and used as vermifuge [12].

\section{Material and Methods}

Collection of plant material

The leaves and stems of (Carica papaya, Eugenia jambolana, and Seriphidium kurrramensis) were obtained from local area of Pakistan.

\section{Processing}

The collected fresh plants materials were examined and old, insect and fungus infected leaves were removed. The soil and dust were removed by washing thoroughly with clean water and air dried in a shaded area. The plants were macerated to small and tiny particles and stored in a screw cap container prior to use.

\section{Microbial isolates}

The microbial isolates namely S. aureus ATCC 25923, Pseudomonas aeruginosa ATCC 27853, E. coli ATCC 25922, Lactobacillus bulgaricus ATCC 11842, Klebsiella pneumoniae ATCC 33152, Bacillus subtilis ATCC 6633, Bifidobacterium bifidum ATCC 11863, Lactobacilus acidophilus ATCC 4356, Listeria monocytogene ATCC 13932 , Enterococcus faecalis ATCC 29212, Salmonella typhimurium ATCC 14028, Saccharomyces cerevisiae ATCC 9763, Bacillus cereus ATCC 11778, Enterobacter sakazakii ATCC 29544 were obtained and clinical isolates, Salmonella spp, Shigella spp, Pseudomonas aeruginosa, Micrococcus luteus, E.coli and Klebsiella pneumoniae, were maintained in glycerol stock at $4^{\circ} \mathrm{c}$ for experimental studies.

\section{Preparation of plant extraction}

Aqueous extraction

Samples of $20 \mathrm{~g}$ were soaked in $100 \mathrm{ml}$ of distilled water, mixed and allowed to soak for 48 hours. At room temperature filtrates were evaporated and Eppendorf's were used to collect the air dried extracts.

\section{Ethanol extraction}

$20 \mathrm{~g}$ of sample was soaked in $100 \mathrm{ml}$ of $95 \%$ ethanol and kept in room temperature for 48 hours. At room temperature filtrates were evaporated and Eppendorf were used to collect the air dried extracts.

Qualitative phytochemical analysis of carica papaya, eugenia jambolana and seriphidium kurramensis

Qualitative tests of different phytoconstituents of the above plants were performed. Different biochemical tests were performed with the extracts to determine the primary and secondary metabolites in the leaves and stem of Carica papaya, Eugenia jambolana and Seriphidium kurramensis.

\section{Alkaloids test}

A fraction of crude extracts were taken and $2 \mathrm{mls}$ of $1 \%$ HCL were added in each respective plant and heated mildly. Few drops of Wagner's reagent were added in the mixtures respectively. Presence of alkaloids was indicated by the turbidity of emerging precipitates. 
Test for flav onoids

Using alkaline reagent

In a test tube $2 \mathrm{ml}$ of $2 \%$ solution of $\mathrm{NaOH}$ was mixed with a fraction of extracts deep yellow color appeared. After adding few drops diluted acid colorless is shown when few drops of diluted acid was added. The presence of flavonoids was indicated.

Test for glycoside

Two $\mathrm{ml}$ of glacial acetic acid in a test tubes containing 2 drops of $2 \%$ solution of $\mathrm{FeCl}_{3}$ was mixed a fraction of extracts. Another test tube was taken and $2 \mathrm{ml}$ of concentrated $\mathrm{H}_{2} \mathrm{SO}_{4}$ was added in to it. The former test tube containing the mixture were poured into it carefully. The appearance of a brown ring at interphase indicated that the glycoside is present.

Test for phenols

$2 \mathrm{ml}$ of $2 \%$ solution of $\mathrm{FeCl}_{3}$ was mixed with a fraction of extract. Presence of phenols were indicated by the appearance of blue, green or black colour.

\section{Test for proteins}

Ninhydrin test

A fraction of crude extracts were taken in a test tubes and $2 \mathrm{mls}$ of $0.2 \%$ solution of ninhydrin were added. They were heated until boiling. Presence of amino acids and proteins were determined by the appearance of violet color.

\section{Test for saponins}

$5 \mathrm{mls}$ of distilled water in a test tubes and fraction of extracts were mixed and rattled quickly. Stable foam was formed and saponin indicated.

\section{Detection of steroids}

A fraction of extracts were mixed with $2 \mathrm{mls}$ of chloroform. Then along the sides of test tubes $2 \mathrm{mls}$ of concentrated $\mathrm{H}_{2} \mathrm{SO}_{4}$ were added respectively. Presence of steroid was indicated by the appearance of red colour in the lower chloroform layer.

\section{Test for tannins}

A fraction of extracts mixed with $2 \mathrm{mls}$ of solution of FeCl3. Presence of tannins was indicated by the appearance of blue, green, or black colour.

\section{Detection of terpenoids}

A fraction of extract were mixed $2 \mathrm{mls}$ of chloroform and allowed to dry by evaporation. Hereafter, $2 \mathrm{mls}$ of concentrated $\mathrm{H}_{2} \mathrm{SO}_{4}$ was poured into it and heated carefully for 2 minutes. Greyish colour appeared and the presence of terpenoids was indicated.

\section{Assay on antimicrobial activity}

The $20 \mathrm{ml}$ of prepared Muller Hinton agar was poured into sterile Petri plates, and allowed to solidify. After solidification a sterile swabs were dipped in an overnight bacterial culture inoculated in broth and were swabbed on the surface of the M.H.A The sterile forceps was used to pick a sterile and the discs were aseptically placed over the inoculated agar plates and ensure firmed by little press. The zone of inhibition was measured after overnight of incubation at $37^{\circ} \mathrm{C}$ and SDA is used in antifungal activity at room temperatures for 48 hours.

\section{Result}

Microbial infection is a serious issue worldwide, although Carica papaya, Eugenia jambolana and Seriphidium kurramense have been known to be medicinal but no report were found about the effect of their water and ethanolic extract on clinical isolate in the local area of Lahore, specially Seriphidium kurramense data was not yet reported in ethanol and water extract in local proximity. In present study was conducted to evaluate antibacterial, antifungal and qualitative phytochemical analysis to determine the alkaloids, carbohydrates, flavonoids, glycosides, phenol, protein, saponin, steroids, tannin and terpenoids in stem and leaves of water and ethanolic extract.

\section{Discussion}

Yahaya A. [13], determined the antimicrobial activities of Carica papaya and its major antimicrobial constituents (phytochemicals Statistical analysis of the result shows that both the extracts demonstrated higher activities against bacteria tested, with the average zone of inhibition of $15.44 \mathrm{~mm}, 14.78 \mathrm{~mm}, 12.92 \mathrm{~mm}$ and $11.31 \mathrm{~mm}$ for Shigella, Escherichia coli, Salmonella typhi and Pseudomonas aeruginosa respectively of the extracts ranges $12.5-100 \mathrm{mg} / \mathrm{ml}$. In the present work the selected strain also showed the significant antimicrobial activity at $20 \mathrm{mg} / \mathrm{ml}$ against lactobacillus bulgaricus ATCC 11842 and E. coli ATCC 25922 both having 7mm with ethanol extracts of stem. While $S$. aureus ATCC 25923 having $7 \mathrm{~mm}$ with aqueous extract of stem. P. aeruginosa clinical, $K$. pneumoniae (ATCC 33152), E.coli clinical, Salmonella clinical, P. aeruginosa (ATCC 27853), M. luteus, Shigella clinical, K. pneumoniae clinical, $B$ cereus (ATCC 11778) and A. niger. No inhibitory results are seen in any fractions of the extracts. He also observed that the Preliminary phytochemical analyses showed that the extracts contain alkaloids, tannins, terpenoids, anthraquinones, reducing sugar, amino acid, flavonoids, saponins, glycosides and phenols. Similarly in this study alkaloids, flavonoids, terpenoids, saponin and tannins were seen.

Anibijuwon [7], determined the antimicrobial activity of Carica papaya leaf that the aqueous extract of leaf shows the higher activ- 


\begin{tabular}{|l|c|c|c|c|c|c|c|c|c|}
\hline & Alkaloids & Flavonoids & Glycosides & Phenol & Protein & Saponin & Steroide & Tannin & Terpenoides \\
\hline CPLW & + & + & - & - & - & + & - & - & + \\
\hline CPSW & - & - & - & - & - & - & - & - & - \\
\hline CPLE & - & + & + & + & - & + & - & + & - \\
\hline CPSE & + & - & - & - & - & + & - & - & - \\
\hline EJLW & + & + & - & + & - & + & - & + & - \\
\hline EJSW & - & - & - & - & - & + & - & - & - \\
\hline EJLE & - & + & + & + & - & + & - & + & - \\
\hline EJSE & + & + & - & - & - & - & - & - & - \\
\hline SKLW & - & + & - & + & + & + & - & + & - \\
\hline SKSW & + & + & - & + & + & + & - & + & - \\
\hline SKLE & - & + & - & - & - & - & - & - & - \\
\hline SKSE & - & + & - & - & + & + & - & - & - \\
\hline
\end{tabular}

Table 1: Represented the qualitative phytochemical analysis in the three medicinal plants

(Carica papaya, Eugenia jambolana and Seriphidium kurramense).

Note: CPLW indicated Carica papaya leaves in water, CPSW indicated Carica papaya stem in water, CPLE represent Carica papaya leaves in ethanol, CPSE represent Carica papaya stem in ethanol, EJLW represent Eugenia jambolana leaves in water, EJSW represent Eugenia jambolana stem in water, EJLE represent Eugenia jambolana leaves in ethanol EJSE represent Eugenia jambolana stem in ethanol, SKLW represent Seriphidium kurramense leaves in water SKSW Seriphidium kurramense stem in water, SKLE represent Seriphidium kurramense leaves in ethanol, SKSE represent Seriphidium kurramense stem in ethanol.

\begin{tabular}{|c|c|c|c|c|c|c|c|c|c|c|c|c|}
\hline STRAIN & CPLW & CPSW & CPLE & CPSE & EJLW & EJSW & EJLE & EJSE & SKLW & SKSW & SKLE & SKSE \\
\hline B.bifidium (ATCC11863) & 0 & 0 & 0 & 0 & 0 & 0 & 0 & 0 & 0 & 0 & 0 & 0 \\
\hline B. cereus (ATCC 11778) & 0 & 0 & 0 & 0 & 0 & 0 & 10 & 0 & 13 & 12 & 8 & 0 \\
\hline B. subtilis (ATCC 6633) & 0 & 0 & 10 & 0 & 6 & 0 & 10 & 0 & 0 & 0 & 0 & 0 \\
\hline E.coli (ATCC 25922) & 0 & 0 & 0 & 7 & 7 & 0 & 15 & 0 & 0 & 0 & 12 & 0 \\
\hline E.coli (clinical) & 0 & 0 & 0 & 0 & 9 & 0 & 14 & 0 & 0 & 0 & 8 & 0 \\
\hline E. faecalis (ATCC 29212) & 0 & 0 & 10 & 0 & 0 & 0 & 0 & 0 & 0 & 0 & 7 & 7 \\
\hline E. sakazakii (ATCC 29544) & 0 & 0 & 0 & 0 & 0 & 0 & 11 & 0 & 8 & 0 & 0 & 0 \\
\hline K. pneumoniae (ATCC 33152) & 0 & 0 & 0 & 0 & 0 & 0 & 14 & 0 & 0 & 0 & 12 & 0 \\
\hline K. pneumoniae (clinical) & 0 & 0 & 0 & 0 & 0 & 0 & 11 & 0 & 0 & 0 & 0 & 0 \\
\hline L. bulgaricus (ATCC 11842) & 0 & 0 & 0 & 7 & 0 & 0 & 11 & 0 & 0 & 0 & 7 & 0 \\
\hline L. acidophilus (ATCC4356) & 0 & 0 & 7 & 0 & 0 & 0 & 0 & 0 & 0 & 0 & 0 & 0 \\
\hline L. monocytogene (ATCC 13932) & 0 & 0 & 0 & 0 & 0 & 0 & 9 & 0 & 0 & 0 & 0 & 0 \\
\hline M. luteus (clinical) & 0 & 0 & 0 & 0 & 0 & 0 & 10 & 0 & 0 & 0 & 10 & 0 \\
\hline P. aeruginosa (ATCC 27853) & 0 & 0 & 0 & 0 & 0 & 0 & 14 & 0 & 0 & 0 & 9 & 0 \\
\hline P. aeruginosa (clinical) & 0 & 0 & 0 & 0 & 0 & 0 & 13 & 0 & 0 & 0 & 9 & 0 \\
\hline S.typhimurium (clinical) & 0 & 0 & 0 & 0 & 0 & 0 & 13 & 0 & 0 & 0 & 10 & 0 \\
\hline S.typhimurium (ATCC 14028) & 0 & 0 & 7 & 0 & 0 & 0 & 7 & 0 & 0 & 0 & 7 & 0 \\
\hline S. aureus (ATCC 25923) & 0 & 7 & 0 & 0 & 0 & 0 & 10 & 0 & 0 & 0 & 0 & 0 \\
\hline Shigella (clinical) & 0 & 0 & 0 & 0 & 0 & 0 & 12 & 0 & 0 & 0 & 10 & 0 \\
\hline
\end{tabular}

Table 2: Representation of antibacterial activity of the three plants.

Note: B. bifidium represent bifidobcterium bifidium B cereus indicated Bacillus cereus, B subtilis represent Bacillus subtilis, E.coli represent Escherichia coli, E. sakazakii represent Enterobacter sakazakii, E. faecalis represent Enterococcus faecalis, K pneumoniae represent Klebsiella pneumoniae, L. acidophilus represent Lactobacillus acidophilus, L bulgaricus represent Lactobacillus bulgaricus, L monocytogenes represent Listeria monocytogenes, M. luteus represent micrococcus luteus, P aeruginosa represent Pseudomonas aeruginosa S. typhimurium represent Salmonella typhimurium, S aureus represent Staphylococcus aureus. 


\begin{tabular}{|c|c|c|c|c|c|c|c|c|c|c|c|c|}
\hline STRAIN & CPLW & CPSW & CPLE & CPSE & EJLW & EJSW & EJLE & EJSE & SKLW & SKSW & SKLE & SKSE \\
\hline A.niger (clinical) & 0 & 0 & 0 & 0 & 0 & 0 & 0 & 0 & 0 & 9 & 0 & 0 \\
\hline S. cerevisae (ATCC 9763) & 0 & 0 & 0 & 7 & 0 & 0 & 0 & 0 & 0 & 0 & 0 & 0 \\
\hline
\end{tabular}

Table 3: Representation the antifungal activity of the three plants.

Note: A. niger represented the Aspergilus niger, S. cerevisae indicated Saccharomyces cerevisae and ATCC American type culture collection.

ty occurred in the bacteria than organic solvent. The phytochemical analysis shows the presence of alkaloids tannins, saponin, glycoside and phenol. In presented work flavonoids, terpenoids and tannins were seen.

Mohammed S [14], observed that the methanol of E. jambolana and Cassia auriculata showed antibacterial activity but not antifungal activity against any of the fungi used. Highest antimicrobial activity was showed by E. jambolana with a minimum concentration $(0.75 \mathrm{mg} / \mathrm{ml})$ against $S$. aureus. In the present study both the ethanol and aqueous extract shows antibacterial activity but no fungal activity against fungi used. Ethanolic leave revealed the highest antimicrobial activity of $15 \mathrm{~mm}$ against E.coli (ATCC 25922). He also detect coumarin, flavonoids, glycosides, phenol, tannins, saponin and steroids on his phytochemical analysis. In the current study alkaloids was not detected from any of the plants.

Shyamala S [15] determined the phytochemical and antibacterial activity of Syzygium cumini leaves extract. The effective results were seen in methanol than aqueous extracts. In the present study the effective result were seen in ethanol than aqueous extracts. Also observed that flavonoids, alkaloids, glycosides, steroids, phenol, saponin, terpenoids, cardiac glycosides and tannins are present. In the current study steroid was not found.

Guilherm F.0 [16]. observed that the leaves extract of Syzygium cumini were effectively seen in the hydro alcoholic extracts against candida krusei. In the present study the ethanolic extract was highly effective on E.coli ATCC 25922.

Syed A.G [17] observed that an endemic species S. kurramense, Andrachina cordifolia and rhazy stricta were strongly phytotoxic plants as compared to other test species. In this present study aqueous extract was more effective against B. cereus ATCC 11778 with $13 \mathrm{~mm}$ of zone of inhibition and no inhibition in K. pneumoniae ATCC 33152 and $K$. pneumoniae clinical in any of the aqueous extract. Ethanol leave extract shows effective in both bacterial and fungal strain except K. pneumoniae.

Kafeel A [18] shows the average inhibition of bacterial strains by $10 \mathrm{mg} / \mathrm{mL}$ ethanolic and aqueous $S$. kurramense extracts. The ethanolic extract showed its highest growth inhibition (74.4\%) toward B. subtilis and its lowest inhibition (32.2\%) K. pneumoniae. In this study also ethanolic extract shows the highest growth inhibition in E.coli (ATCC 25922) and $K$ pneumoniae (ATCC 33152) both having $12 \mathrm{~mm}$ zone of inhibition and the lowest inhibition in S. typhimurium (ATCC 14028), L. bulgaricus and E. faecalis (ATCC 29212 ) both having $7 \mathrm{~mm}$ zone of inhibition at $20 \mathrm{mg} / \mathrm{ml}$. He also observed that fungal inhibition assays using $5 \mathrm{mg} / \mathrm{mL}$ crude ethanolic and aqueous extracts of $S$. kurramense. For the ethanolic extract, good inhibition was observed for $F$. solani. Moderate inhibition was observed for Aspergillus niger and P. florida. Slight inhibition was observed form A. flavus and $R$. solani. The aqueous extract inhibited the growth of Alternaria solani by $51.5 \%$ and P. florida by $28.4 \%$ but did not inhibit the growth of the other tested fungi. The average inhibition of fungal growth by $10 \mathrm{mg} / \mathrm{mL} S$. kurramense ethanolic extract observed against Aspergillus niger, F. solani and P. florida. Moderate activity of $A$. flavus and R. solani. For $10 \mathrm{mg} / \mathrm{mL}$ aqueous extract, Moderate activity observed against $A$. solani and $P$. florida on present study.

\section{Conclusion}

In this study evaluation of antibacterial activity, anti-fungal activity and phytochemical analysis of Carica papaya, E. jambolana and $S$. kurramense leaves and stem in different solvent (water and ethanol) was performed. It was concluded that from the results obtained that the plants parts fractions were significant in possessing antibacterial, antifungal activities. Among all the ethanol was found to be most important fraction at its high concentrations.

\section{Interest of Conflict}

The authors declare that they have no interest of conflict.

\section{Acknowledgements}

Institute of Molecular Biology and Biotechnology, The University of Lahore.

\section{Bibliography}

1. Alemtshay T., et al. "In vitro antimicrobial activity of plants used in traditional medicine in Gurage and Silti zones, south central Ethiopia". Complementary and Alternative Medicine 15 (2015): 286. 
2. Parastoo K.A., et al. "A study of antimicrobial activity of few medicinal herbs". Asian Journal of Plant and Research.2.4 (2012): 496-502.

3. Mozghan A., et al. "Antimicrobial effect of Ginger (Zingiber officinale) and mallow (Malva sylvestris) hydro alcoholic extracts on four pathogen bacteria". Der Pharmacia Lettre 8.1 (2016): 181-187.

4. Nagumanthri V., et al. "Invitro antimicrobial activity of Acacia nilotica, Ziziphus mauritiana, Bauhinia variegate and Lantana camara against some clinical isolated strains". Iranian Journal of Science and Technology A 2 (2012): 213-217.

5. Kahkashan P., et al. "Invitro antimicrobial activity if some medicinal plants found in Saudi arabia". Journal of Pure and Applied Microbiology 8.3 (2014): 2129-2134.

6. Selvamohan T., et al. "Antimicrobial activity of selected medicinal plant against some selected human pathogenic bacteria". Advances in Applied Science Research 3.5 (2012): 3374-3381.

7. Anibijuwon II and Udeze AO. "Antimicrobial activity of Carica papaya (pawpaw leaf) on some pathogenic organisms of clinical origin from south-western Nigeria". Ethnobotanical leaflets 13.8 (2009): 50-64.

8. Jadhav RL., et al. "Use of Eugenia jambolona fruit extracts as a natural indicator in acid base titration". International Journal of Chemical Science 6.2 (2008) 637-642.

9. Denis MO., et al. "Antimicrobial activity of Eugenia jambolana seeds against food borne isolates". Journal of Scientific and Innovative Research 4.6 (2015): 232-236.

10. Nusrat S., et al. "Isolation, characterization of flavonoids from seriphidium oliverianum and their antioxidant and anti-urease activities". Journal of Chemical Society of Pakistan 36.3 (2014): 517-523.

11. Abhay KP and Pooja S. "Literature review on chemical composition, antimicrobial, insecticidal and antioxidant activities of essential oils". Medicines 4.68 (2017): 1-15.

12. Wahid H., et al. "Tradable and conservation status of medicinal plants at kurram valley, Parachinar, Pakistan". Journal of Applied Pharmaceutical Science 2.10 (2012): 066-070.

13. Yahaya A and Ali M and Idris A. "Antibacterial Activity and Phytochemical Screening of Carica papaya on some Enteric Bacterial Isolates of Public Health Importance". Greener Journal of Biological Sciences (2017): 2276-7762.
14. Mohammed S.S., et al. "Antimicrobial activity and phytochemical analysis of selected indian folk medicinal plants". International Journal of Pharma Sciences and Research 1.10 (2010): 430-434.

15. Shyamala SG and Vasantha K. "Phytochemical screening and antibacterial activity of Syzygium cumini(L)(myrtaceae) leaves extracts". International Journal of Pharm Tech Research 2.2 (2010): 1569-1573.

16. Guilherme F.O., et al. "Antimicrobial activity of Syzygium cumini(myrtaceae)leaves extracts". Brazilian Journal of Microbiology 38 (2007): 381-384.

17. Syed AG., et al. "Chemotypic variation and phytotoxic studies of essential oils of endemic medicinal plants, Seriphidium kurramense, from Pakistan". Journal Medicinal Plants Research 4.4 (2010): 309-315.

18. Kafeel A., et al. "Antimicrobial, hemagglutination and phytotoxic activity of crude ethanolic and aqueous extracts of Seriphidium kurramense". Journal of Traditional Chinese Medicine 38.3 (2018): 433-438.

\section{Volume 2 Issue 12 December 2019}

(C) All rights are reserved by Nureen Zahra., et al. 